\title{
Diagnosis of adrenal failure in critically ill patients
}

\section{Diagnóstico de insuficiência adrenal em pacientes críticos}

Rafael Barberena Moraes', Mauro A. Czepielewski², Gilberto Friedman', Evandro Lucas de Borba ${ }^{3}$

\section{SUMMARY}

In the last two decades there was important evolution on the knowledge of the function of the hypothalamic-pituitary-adrenal axis. In the last decade, the expression "relative adrenal insufficiency" (RAI) was created, and more recently "critical illness-related corticosteroid insufficiency" (CIRCI) was used to designate those patients in which cortisol production was not sufficiently increased in stress situations. Patients with $\mathrm{CIRCI}$ have elevated hospital morbidity and mortality. Currently, there is a wide discussion about diagnostic criteria for this dysfunction. Besides basal cortisol, some publications now study the role of other tests, such as cortrosyn test - either in low $(1 \mu \mathrm{g})$ or high doses $(250 \mu \mathrm{g})$; free cortisol, salivary cortisol, metyrapone test and others. With this review, we aimed at summarizing the results of the most influent papers that intended to define diagnostic criteria for $\mathrm{CIRCl}$. We also suggest an approach for $\mathrm{CIRCl}$ diagnosis and make it clear that the decision about steroid therapy in septic shock patients is matter apart from RAI. Arq Bras Endocrinol Metab. 2011;55(5):295-302

\section{Keywords}

Adrenal insufficiency; sepsis; septic shock; cortrosyn; steroid therapy; CIRCI (critical illness-related corticosteroid insufficiency); RAI (relative adrenal insufficiency)

\section{SUMÁRIO}

Nas últimas décadas, houve uma importante evolução no conhecimento sobre a função do eixo hipotálamo-pituitária-adrenal. Na última década, foi cunhada a expressão “insuficiência adrenal relativa" (IAR) e, mais recentemente, a expressão "insuficiência adrenal relacionada à doença grave" (CIRCI) foi utilizada para designar aqueles pacientes nos quais a produção de cortisol não era suficientemente elevada em situações de estresse. Pacientes com $\mathrm{CIRCl}$ apresentam elevada morbidade e mortalidade em hospitais. Atualmente, há uma ampla discussão sobre os critérios de diagnóstico para essa desordem. Além do cortisol basal, algumas publicações analisaram o papel de outros testes, tais como o teste de estímulo com ACTH (cortrosina), com doses baixas ( $1 \mathrm{mg}$ ) ou altas (250 mg), cortisol livre, cortisol salivar, teste da metirapona e outros. $\mathrm{O}$ objetivo desta revisão foi resumir os resultados dos artigos mais importantes que buscaram definir os critérios de diagnóstico para a $\mathrm{CIRCI}$. Também sugerimos uma abordagem para o diagnóstico da $\mathrm{CIRCl}$ e deixamos claro que a decisão sobre a terapia com esteroides em pacientes em choque séptico é uma questão separada da IAR. Arq Bras Endocrinol Metab. 2011;55(5):295-302

\section{Descritores}

Insuficiência adrenal; sepse; choque séptico; cortrosina; terapia com esteroides; CIRCI (insuficiência adrenal relacionada à doença grave); IAR (insuficiência adrenal relativa)
1 Intensive Care Unit, Hospital de Clínicas de Porto Alegre, Porto Alegre, RS, Brazil

${ }^{2}$ Endocrinology Unit, Hospital de Clínicas de Porto Alegre, Graduate Studies Program in Medical Science: Endocrinology, Faculdade de Medicina, Universidade Federal do Rio Grande do Sul (UFRGS), Porto Alegre, RS, Brazil ${ }^{3}$ Faculdade de Medicina, UFRGS, Porto Alegre, RS, Brazil
Correspondence to: Rafael Barberena Moraes Rua Erechim, 100/31

Porto Alegre, RS, Brasil 90830-000

tchemoraes@hotmail.com

Received on Mar/30/2011 Accepted on Apr/24/2011

\section{INTRODUCTION}

$\mathrm{A}^{\mathrm{s}}$ most a century ago, researchers had already described that adrenal glands increase their trophism in response to infection (1). In the 1960s, studies in animal models with induced endotoxemia concluded that steroids in high doses decreased mortality. These results were the basis for human studies and steroid use in septic shock treatment in humans, for 30 years (2).

Until the 1990s, many trials reported divergent results about the role of steroids in septic shock. In these trials, steroids were employed in doses as high as 120 $\mathrm{mg} / \mathrm{kg} /$ day of methylprednisolone, in patients with 
sepsis but without septic shock, late in the course of shock, and for a brief period (3-4 days).

Aiming at blocking the inflammatory cascade, to prevent tissue lesion and "excessive" inflammation due to sepsis, the use of corticosteroids in high doses survived as a practice until the 1990s, when two meta-analyses definitively abolished this practice $(3,4)$.

Lefering and cols. in 1995 (3) carried out a meta-analysis of 10 trials and concluded that steroids in high doses brought no benefits to septic shock patients. Another meta-analysis conducted by Zeni and cols., in 1997 (4), evaluated 8 trials and concluded that steroids in high doses increased mortality in septic shock. It seemed that discussion about steroids in sepsis had ended, when steroids started to be used in critical care in another way.

The knowledge that a substantial increase in cortisolemia is expected in critical care situations, such as septic shock, surgery, trauma and others, and that some patients exhibit a blunted response, led some experts to propose a supplementation of physiological doses of cortisol to these patients.

The expression "relative adrenal insufficiency" (RAI) was suggested to describe those patients without previous adrenal dysfunction who, during critical illness, had inadequate cortisol level for the severity of the disease (5). Since the 1990s, many trials have employed steroids in septic shock in a different way than in the past: in lower, physiological doses (hydrocortisone, $200-300 \mathrm{mg} /$ day, in 3-4 doses); sooner; in patients with septic shock (not in patients with sepsis or severe sepsis); or for a longer time (5-7 days), obtaining positive results, mainly in the hemodynamic profile $(6,7)$.

In spite of the evolution on knowledge about the functions of the HPA axis in critical care patients in the last 20 years, the procedures practitioners follow to identify critical care patients is still a matter of divergence.

In this article, we reviewed the studies that evaluated the diagnosis of adrenal dysfunction in critical care patients, and discuss the current indications for the use of steroids in cases of septic shock.

\section{Physiopathology of adrenal insufficiency in critical care patients}

In stress situations, the physiological response is the activation of the HPA axis. Septic shock is one of the strongest stimulators of the HPA axis, leading to increases in serum levels of cortisol-releasing hormone
$(\mathrm{CRH})$, adrenocorticotropic hormone $(\mathrm{ACTH})$, arginine vasopressin (AVP), and cortisol in acutely ill patients. Patients that are not able to activate the HPA axis and cortisol production in critical situations have increased morbidity and mortality $(8,9)$.

Simultaneously, production of mineralocorticoids is increased. Renin and angiotensin are the strongest stimulators for aldosterone release (and not the hypothalamus and pituitary gland). Incapacity to increase aldosterone levels is also related to increased morbidity and mortality (10).

The understanding of these mechanisms was fundamental for the comprehension that the incapacity to increase adrenal function under stress situations is a dysfunction. Cortisol production is the final step of the activation of the HPA axis. In septic shock patients (sepsis inducing tissue hypoperfusion that is not reverted with adequate volume resuscitation), it is expected that the hypothalamus will increase $\mathrm{CRH}$ production.

$\mathrm{CRH}$, by means of sympathetic stimulation, increases the release of catecholamines, epinephrine and norepinephrine, substances responsible for vasoconstriction and positive inotropism. CRH also stimulates the posterior pituitary gland to release AVP, which causes water retention and vasoconstriction. The action of AVP in V2 receptors on the collecting ducts of the kidney causes free water to be reabsorbed. The action of AVP in Vl receptors, located in vascular smooth muscle, is responsible for vasoconstriction.

No only CRH, but also AVP, are important stimulators of ACTH release in the anterior pituitary gland. ACTH, by means of its action in adrenal glands, is the strongest stimulus to glucocorticoid production. Cortisol is the main glucocorticoid produced in humans (Figure 1).

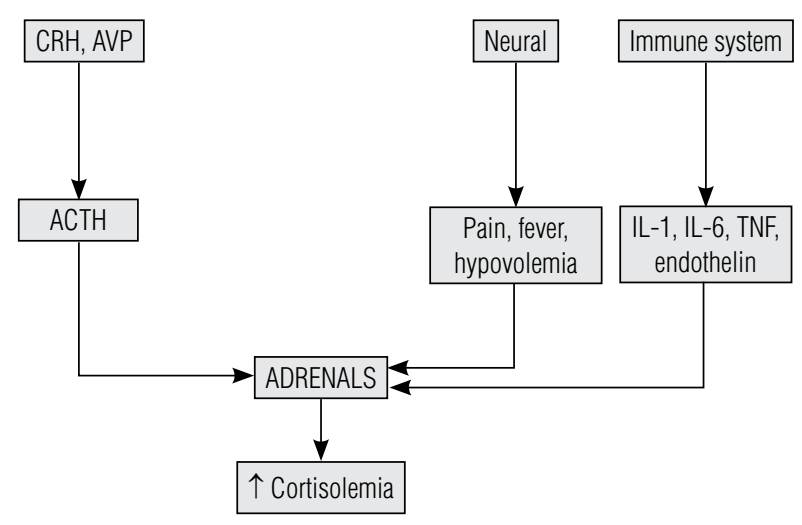

Figure 1. Adrenal stimulation in the critically ill patient. 
Although cortisol remains elevated all over the course of critical illness, the hypothalamus and pituitary gland exhibit different responses in acutely and in chronic ill patients (11). In acutely ill patients (under 7 days of critical illness), the physiological response is the elevation in serum levels of these hormones $(\mathrm{CRH}$, ACTH, AVP and cortisol). These changes aim at increasing the supply of energy to the tissues in a hypercatabolic state. In chronic ill patients, although cortisol remains elevated, serum levels of CRH, AVP and ACTH decrease. The meaning of this phenomenon is a matter of divergence. The "draining" of the hypothalamus and pituitary gland due to chronic critical illness may be interpreted as an endocrinological dysfunction, but some experts argue that this may be an adaptive mechanism to decrease catabolism (12).

Maintainance of elevated cortisol levels despite the drop in pituitary hormones seems to be caused by non-ACTH mediated mechanisms, such as interleukins, tumor necrosis factor (TNF), endothelin, and atrial natriuretic factor (ANF) (13).

The half-life of cortisol is $60-120$ minutes and its depuration occurs by means of hepatic metabolism and glomerular filtration. Usually, cortisol is secreted in pulses, with morning peaks. In the critical care patient, cortisol remains elevated all day long, losing its circadian rhythm. The level of circulating cortisol is directly related to level of stress to which the patient is submitted.

Among the functions of glucocorticoids in sepsis are the modulation of inflammation, stimulation of synthesis and action of catecholamines (increasing tissue perfusion), and actions on the metabolism of lipids, proteins, and carbohydrates.

Cortisol is synthesized from cholesterol, whose access to the intracellular space is limited by the HDL-receptor. Around $90 \%$ of circulating cortisol is bound to serum proteins, mainly cortisol binding-globulin (CBG) and albumin. In stress situations, serum levels of CBG and albumin decrease, increasing the free fraction of cortisol, the biologically active form of the hormone. Similar to CBG and albumin, serum levels of HDL also decrease around $50 \%$ on the first days of sepsis, returning to baseline levels after 4 weeks (14).

Recent studies evaluated the role of the enzyme 11 $B$-hydroxysteroid dehydrogenase (11B-HSD), which controls the cortisol (active form) to cortisone (inactive form) relationship. Experimental data and in vivo studies suggest that, during septic shock, inflamma- tory mediators like TNF and interleukins activate $11 B$ -HSDl, increasing cortisolemia (15).

Cortisol actions are essential for homeostasis in stress. Many interventions can inhibit cortisol synthesis in an intensive care unit (ICU), such as the use of dopamine, antifungals or etomidate.

\section{DIAGNOSIS}

\section{Baseline total cortisol and free cortisol}

Because the physiological response to stress is the increase in cortisol levels, the first approach suggested to diagnose adrenal dysfunction in critical care patients is to measure total random cortisol, without exogenous stimulation, once stress situations, such as hypotension, pain and others, are strong stimuli to cortisol production. That is, the clinical situation that the patient is submitted to would function as the stimulus to check if the adrenal exhibits adequate response to stress.

In patients who are not under stress situations, baseline cortisol higher than $18 \mu \mathrm{g} / \mathrm{dL}$ has high negative likelihood ratio to adrenal failure. In critical care patients, this cutoff point proved to be inadequate to identify RAI, once trials documented levels much higher than that under stress situations, in patients without adrenal dysfunction. That is, such level does not exclude RAI diagnosis. Some trials documented that, in septic shock, trauma or post-operative period, baseline cortisol levels higher than $25 \mu \mathrm{g} / \mathrm{dL}$ are usual, suggesting this value as a cutoff point for RAI diagnosis (16).

However, many experts criticize this cutoff point for RAI derived from an influent study published in 2000, whose objective was to identify adrenal variables related to mortality in the ICU. In this trial, baseline cortisol $\geq 26 \mu \mathrm{g} / \mathrm{dL}$ showed sensitivity of only 0.55 and specificity of only 0.58 (17). In this study, cortisol variation $\leq 9 \mu \mathrm{g} / \mathrm{dL}(\Delta \leq 9 \mu \mathrm{g} / \mathrm{dL})$ after the $250 \mu \mathrm{g}$ of cortrosyn test showed sensitivity of 0.68 and specificity of 0.65 , more accurate than baseline cortisol to predict mortality in the $28^{\text {th }}$ day of ICU stay. The result of this study was the basis for future trials that used this parameter ( $\Delta$ cortisol $\leq 9 \mu \mathrm{g} / \mathrm{dL}$ after cortrosyn test) to define which patients should receive steroid therapy in septic shock.

The current understanding is that under stress situations, "low" baseline cortisol has high positive likelihood ratio to RAI, and "high" baseline cortisol has high negative likelihood ratio to RAI. However, there is no consensus on what values are "low" or "high". Most experts agree that baseline cortisol lower than 
$10 \mu \mathrm{g} / \mathrm{dL}$ is low, and that baseline cortisol greater than $34-44 \mu \mathrm{g} / \mathrm{dL}$ is high. Even so, these cutoff values are not validated for guiding steroid therapy. Baseline cortisol $<10 \mu \mathrm{g} / \mathrm{dL}$ has high specificity in CIRCI diagnosis (specificity, 1; 95\% CI, l-1) (18).

As previously described, around $90 \%$ of circulating cortisol is bound to serum proteins (albumin and CBG), and only $10 \%$ is free cortisol. Some alterations typical of critically ill patients raise more doubts about the applicability of total cortisol in RAI diagnosis.

In acutely ill patients, serum proteins decrease markedly, in part, due to the increased synthesis of acute reactants. Many experts question if this phenomenon does not invalidate total cortisol measurement in critically ill patients $(19,20)$.

This concern led to studies on the role of free cortisol in RAI diagnosis, even at baseline, after stimulation tests. Free cortisol can be directly measured or calculated from the relationship between total cortisol and CBG, although this method may be less accurate once it does not consider the effect of hypoalbuminemia.

We also emphasize that cutoff values of free cortisol for CIRCI diagnosis are less studied than total cortisol. Hamrahian and cols. (20) suggested baseline free corti$\mathrm{sol}<2.0 \mu \mathrm{g} / \mathrm{dL}$ or free cortisol after cortrosyn test $<3.1$ $\mu \mathrm{g} / \mathrm{dL}$ as cutoff values to diagnose CIRCI. However, more studies are necessary to unveil the relationship of baseline free cortisol and stimulated free cortisol with mortality or response to steroid therapy, before making recommendations on the use of free cortisol. This study illustrated that in hypoalbuminemic patients (albu$\min <2.5 \mathrm{~g} / \mathrm{dL}$ ), total baseline cortisol and cortisol variation after cortrosyn tests showed lower levels than in patient with normoalbuminemia. These lower values may be responsible for the overdiagnosis of CIRCI in hypoalbuminemic critically ill patients, once baseline free cortisol or its increase after cortrosyn tests are not related to serum proteins.

The Annanne's trial that compared diagnostic methods, using the metyrapone test as the standard reference, concluded that calculated free cortisol did not improve the accuracy of CIRCI diagnosis (18). Another trial, published in 2008, corroborates this finding (21).

Measurement of free cortisol or CBG is not available in most hospitals. Thus, even if free cortisol measurement seems to be more physiological than total cortisol, its applicability is currently very restricted. Besides, until now, it did not prove to be superior to total cortisol in the diagnosis of CIRCI. We also understand that more studies are necessary to identify cutoff va- lues for CIRCI, as well as cutoff values to define which patients would benefit from steroid therapy, as current knowledge is more broadly based on total cortisol.

\section{Low dose $(1 \mu \mathrm{g})$ cortrosyn test}

The use of cortrosyn, a synthetic analogous of ACTH, as a stimulation test for the diagnosis of cortisol failure, is relatively validated and widely used in non-critically ill patients $(22,23)$. To this moment, few trials employed the low dose test to identify CIRCI in critically ill patients. Supposedly, the low dose test has many advantages over the high dose test $(250 \mu \mathrm{g})$, but more trials are needed to confirm this hypothesis. One of these advantages comes from the knowledge that the low dose test is more physiological than the high dose one, because it is able to stimulate the whole HPA axis, while the high dose test stimulates exclusively the adrenal glands, bypassing the hypothalamus and pituitary gland. Other potential advantage is that the low dose test simulates ACTH levels similar to those observed in septic shock $(100 \mathrm{pg} / \mathrm{mL})(24)$, while the high dose test generates much higher concentrations.

One of the first studies that evaluated cortisol response to the low dose cortrosyn test, published in 1999, concluded that unresponsive patients had their arterial pressure increased after hydrocortisone supplementation (25).

Another study published in 2005 (26), which defined unresponsive patients to low dose test as showing cortisol variation $\leq 9 \mu \mathrm{g} / \mathrm{dL}$, exhibited an interesting result. It identified a group of patients responsive to the high dose test, who were unresponsive to the low dose test and showed the worst prognosis. These data suggest that the low dose test may identify patients with adrenal dysfunction who are not identified by the high dose test.

Our group recently concluded a study with the objective of comparing both tests in a cohort of 74 septic shock patients. Our data showed that the low dose test had accuracy similar to the high dose test in the identification of non-survivors and vasopressor withdrawal. We also concluded that the low dose test identified more patients with increased mortality and vasopressor dependency. This study also illustrated that cortisol variation induced by both tests was different (it was greater in the high dose test), but with moderate to strong correlation, mainly in the population with baseline cortisol between 10-34 $\mu \mathrm{g} / \mathrm{dL}$.

The dissemination of the high dose cortrosyn test as a reference standard in the diagnosis of adrenal insu- 
fficiency in critical care patients is related to trials that associated low cortisol variation induced by this test with increased mortality, time of vasopressor therapy, as well as identification of patients that should receive hydrocortisone supplementation. Although the current decision about steroid supplementation is dissociated from cortisol variation after cortrosyn test, we understand that recommending the utility of the low dose test in the diagnosis of CIRCI can only be done after trials that link the result of the test with adrenal dysfunction, as identified by a real standard reference test (such as the metyrapone test, instead of the high dose cortrosyn test), or by its ability to identify patients that would benefit from steroid therapy.

\section{High dose cortrosyn test $(250 \mu \mathrm{g})$}

One of the first references to high dose cortrosyn test in critical care patients is from 1991 (25). In spite of the small number of patients, the authors observed that among patients with cortisol variation after cortrosyn test $\leq 9 \mu \mathrm{g} / \mathrm{dL}$, mortality rate was $100 \%$ (13 patients), while mortality rate was only $30 \%(6 / 19)$ among the patients with cortisol variation $>9 \mu \mathrm{g} / \mathrm{dL}$. This was the first report to point out that this test was able to identify critically ill patients with adrenal dysfunction.

Nine years later, another trial analyzed this hypothesis (15). This trial was designed to identify factors associated with mortality in critical care patients, with special attention to cortisol levels and cortisol variation. In this trial, cortisol variation after the high dose test was the adrenal variable that best correlated with mortality. Since then, it was adopted as the standard test in the identification of adrenal dysfunction in ICU patients. It is worth remembering that, until this trial, it was a matter of debate if a small variation in cortisol levels under stress was a physiological response or a dysfunction. Thus, this trial was crucial for critical care physicians to accept that some patients exhibit adrenal dysfunction, and that this dysfunction is a cause of mortality in the ICU. In this trial, the area under the ROC curve was 0.68 , with $\Delta$ $=9 \mu \mathrm{g} / \mathrm{dL}$ as the most accurate point, with sensitivity of 0.68 and specificity of 0.65 . In spite of the only moderate accuracy, this was the adrenal variable that best correlated with mortality in critically ill patients.

The result of this trial was the foundation for the same authors to carry out the trial that resuscitated steroid use in septic shock (27). Two years later, Annane et al. published the results of a randomized clinical trial conducted in 19 ICUs of France with 299 patients.
Patients received hydrocortisone $(50 \mu \mathrm{g}$, i.v., every 6 hours) plus fludrocortisone (50 $\mu \mathrm{g}$ tablet once daily), or matching placebos. After the result of the cortrosyn test, the drugs were discontinued in patients with $\Delta$ cortisol $>9 \mu \mathrm{g} / \mathrm{dL}$. Patients with $\Delta$ cortisol $\leq 9 \mu \mathrm{g} / \mathrm{dL}$ received therapy for 7 days. In this trial, patients with $\Delta$ cortisol $\leq 9 \mu \mathrm{g} / \mathrm{dL}$ who received hydrocortisone and fludrocortisone showed decreased mortality, 53\%vs. $63 \%$ in the placebo group (hazard ratio, $0.67 ; 95 \%$ confidence interval, $0.47-0.95 ; \mathrm{p}=0.02$ ). Survival analysis by Kaplan-Meyer method showed less time to vasopressor withdrawal among treated patients.

After this trial, most ICUs around the world began to use the response to the high dose cortrosyn test to decide which septic shock patients would receive or not steroid therapy. This approach was suggested by the guidelines of European Society of Intensive Care Medicine published in 2004, but this recommendation was removed in the updated guidelines of 2008 (28). We should remember that, differently from the practice until 1990s, when high dose steroids were given to septic patients (not in septic shock) aiming at their immunosupression, the current approach is to use smaller doses (200-300 mg/day, divided into 3-4 doses or continuous infusion) in the course of sepsis, in patients with septic shock using vasopressor, starting steroids in the first hours of shock.

Many questions arisen about the use of the $250 \mu \mathrm{g}$ cortrosyn test. As previously described, such high dose generates corticotropin levels much higher than those generated by septic shock. Thus, patients responsive to such dose may not actually be able to increase adequately their cortisol levels when facing another stimulus, such as shock or hypoglycemia, decreasing the sensitivity of the test. Some researchers agree with this hypothesis, showing that the high dose test has high specificity and low sensitivity $(5,29)$.

In spite of the criticism, the $250 \mu \mathrm{g}$ cortrosyn test is the most studied diagnostic test for CIRCI in critical care patients, and is the test that showed the most accurate relationship with morbidity and mortality, although currently consensus is that the decision about steroid supplementation in septic shock is not dependent on the results of the test.

\section{Metyrapone test}

By means of the inhibition of the enzyme 11- $B$-hidroxylasis, metyrapone inhibits the conversion of 11-deoxycortisol to cortisol. A sharp decrease in serum cortisol 
and elevation in serum levels of 11-deoxycortisol and ACTH are expected in response to the metyrapone test.

The concern about blocking cortisol synthesis after metyrapone use is one of the causes that led researchers not to study this test in septic shock patients until recently. In 2006, Annane and cols. (27) published a study using the metyrapone test as the standard test for CIRCI diagnosis. In this study, the combination of basal cortisol $<10 \mu \mathrm{g} / \mathrm{dL}$ and cortisol variation $\leq 9 \mu \mathrm{g} / \mathrm{dL}$ after the high dose cortrosyn test was the best predictor of CIRCI, with specificity of 0.96 (CI 0.87-1), but sensitivity of only 0.45 (CI $0.26-0.63$ ). This trial was the most influent in the consensus proposed in 2008 (30). All patients received steroids in the 24 hours following the test. In this trial, cortisol variation after the $250 \mu \mathrm{g}$ cortrosyn test $\geq 16.8 \mu \mathrm{g} / \mathrm{dL}$ was predictive of absence of adrenal insufficiency.

Although the metyrapone test is considered a gold standard in the diagnosis of adrenal insufficiency in non-critically ill patients, we believe that greater experience with this methodology is necessary in critical care patients before making recommendations about the metyrapone test in the diagnosis of CIRCI. The lack of access to metyrapone in many countries precludes trials for the evaluation of its role in critical care patients, as well as its posterior use.

\section{Salivary cortisol}

The measurement of cortisol in saliva dispenses venous puncture and drawing blood. Differently from serum cortisol, salivary cortisol is predominantly - around $85 \%$ - in the free form, and it is strictly related with serum cortisol. Increases in serum cortisol generate increases in salivary cortisol only 2-3 minutes later.

The wider access to the measurement of salivary cortisol make possible to estimate serum free cortisol, and is an interesting alternative approach to the measurement of free cortisol. However, it must be emphasized that collection of saliva in critically ill patients is not widely standardized and samples are harder to be collected than in ambulatory patients. Many situations in a critical care scenario, like coma or mechanical ventilation, makes it impossible to obtain the collaboration of the patient for saliva collection. This makes salivary cortisol harder to obtain than serum cortisol, and more prone to bias. Besides, anemia, oral bleeding, oral candidiasis, use of chlorhexidine (oral decontamination) interfere with cortisol measurement in saliva, limiting its use in critical care patients.

Salivary and serum cortisol levels have a strong correlation, even in critically ill patients $(29,31)$. Even so, more trials are necessary to validate levels of salivary cortisol for CIRCI diagnosis.

\section{Insulin-induced hypoglycemia}

Hypoglycemia is among the strongest stimuli for cortisol synthesis and, with the metyrapone test, insulin-induced hypoglycemia is considered the gold standard in the diagnosis of adrenal insufficiency in non-critically ill patients. However, it is considered impractical in the critical care patient. First, there is an obvious concern in inducing hypoglycemia in an already unstable patient. Second, recent trials proved that hyperglycemia and hypoglycemia are deleterious to critical care patients, and euglycemia became a standard of care for these patients.

Thus, until this moment, no trials evaluated the role of insulin-induced hypoglycemia in the diagnosis of CIRCI, and it is improbable that ethics committees would approve studies with this method in critical care patients.

\section{CONSENSUS}

In 2008, the American College of Critical Care Medicine developed a consensus with recommendations for the diagnosis and management of corticosteroid insufficiency in critically ill patients (30). The consensus proposed baseline cortisol $<10 \mu \mathrm{g} / \mathrm{dL}$ or cortisol variation after $250 \mu \mathrm{g}$ of cortrosyn $<9 \mu \mathrm{g} / \mathrm{dL}$ as the diagnostic criteria for CIRCI. This recommendation was based mainly on the Annane's trial that used metyrapone as the gold standard for CIRCI diagnosis (18), where this criterion showed high specificity but low sensibility. Some experts showed the limitations of this recommendation (32).

We agree that there is enough evidence to relate low cortisol variation to adrenal dysfunction in critically ill patients. Even so, we argue that such variation is an important parameter in intermediary baseline cortisol, once high baseline cortisol excludes adrenal dysfunction, as it is evidence of adequate adrenal response to stressors.

We agree that low baseline cortisol is laboratory evidence of CIRCI, and the threshold of $10 \mu \mathrm{g} / \mathrm{dL}$ is validated as a specific value. Our group and other 
authors proposed that adrenal dysfunction should be diagnosed when baseline cortisol is inadequately low $(<10 \mu \mathrm{g} / \mathrm{dL})$, and that adrenal dysfunction should be excluded when baseline cortisol is too high (> 34-44 $\mu \mathrm{g} / \mathrm{dL}$ ) (33). In patients with baseline cortisol between $10 \mu \mathrm{g} / \mathrm{dL}$ and $34 \mu \mathrm{g} / \mathrm{dL}$, we propose the use stimulation tests, such as cortrosyn tests, to diagnose adrenal dysfunction, as shown in figure 2 .

\section{Baseline total cortisol (BC)}

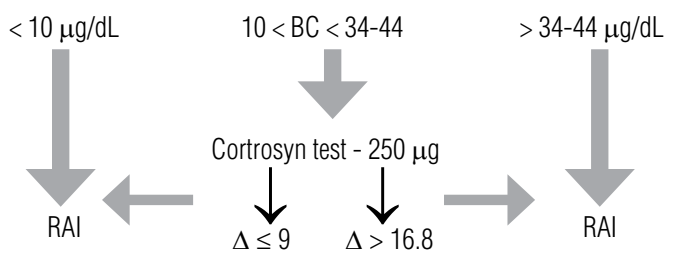

Figure 2. Proposed algorithm to diagnose adrenal dysfunction in critically ill patients. RAl: relative adrenal insufficiency.

Although the focus of this review is the role of diagnostic tests in the diagnosis of adrenal dysfunction in critically ill patients, we also would like to emphasize that, currently, the diagnosis of adrenal failure is dissociated from the decision on the use of steroid supplementation in septic shock patients. Most of the researchers agree that steroid supplementation decrease time to vasopressor withdrawal in septic shock (34). The effect of steroids on mortality is much controversial. Recent systematic reviews and meta-analyses concluded that steroids decrease mortality in septic shock $(35,36)$.

Currently, guidelines suggest that "intravenous hydrocortisone be given only to adult septic shock patients after blood pressure is identified to be poorly responsive to fluid resuscitation and vasopressor therapy" (28). This recommendation makes clear that there still is a lot of doubts about the ability of adrenal tests to identify patients with adrenal dysfunction that are responsive to steroid supplementation. The recommendation is to use hydrocortisone $200-300 \mathrm{mg}$ /day divided into 3-4 doses or continuously, with gradual withdrawal. Finally, it is important to realize that this recommendations are related to the use of steroids in septic shock, not about use of steroids in adrenal dysfunction, a situation in which experts currently make no therapeutic recommendation.

\section{Research and perspectives}

Beyond the role of the tests previously described in the diagnosis of CIRCI, there is growing interest in the role of alternative pathways to stimulate the adrenals (other than ACTH), such as vasopressin and inflammatory mediators, like interleukins, which seems to play a central role, once many patients exhibit high cortisol and low ACTH levels.

Besides, it was proposed that some patients show corticoids insufficiency secondary to peripheral tissue resistance to cortisol action, instead of adrenal dysfunction. How to identify such resistance is under study but, until this moment, there are no recommendations on this issue (37).

In conclusion, as previously exposed, more studies are necessary to identify critical care patients with adrenal dysfunction. Insulin-induced hypoglycemia, although considered a standard in non-critically ill patients, is impractical in ICU patients. Experience with the metyrapone test is still lacking, and its poor availability makes it unlikely to be used worldwide.

Although free cortisol measurement seems to be more physiological, this methodology is currently restricted to a few centers, and did not prove to be more accurate than total cortisol in diagnosing CIRCI. Free cortisol can also be measured in saliva. Although this technique has become more widespread in non-critical care patients, more trials are necessary in stressed patients to validate this technique.

In spite of some bias, mainly in hypoalbuminemic patients, total cortisol measurement is currently the most accepted method in the diagnosis of CIRCI, which is based on its baseline level and its variation after the $250 \mu \mathrm{g}$ cortrosyn test.

Disclosure: no potential conflict of interest relevant to this article was reported.

\section{REFERENCES}

1. Scott WJM. The Influence of the adrenal glands on resistance. J Exp Med. 1924;39:457-71.

2. Hinshaw LB, Coalson JJ, Benjamin BA, Archer LT, Beller BK, Kling OR, et al. Escherichia coli shock in the baboon and the response to adrenocorticosteroid treatment. Surg Gynecol Obstet. 1978;147:545-57.

3. Lefering R, Neugebauer EA. Steroid controversy in sepsis and septic shock: a meta-analysis. Crit Care Med. 1995;23:1294-303.

4. Zeni F, Freeman B, Natanson C. Anti-inflammatory therapies to treat sepsis and septic shock: a reassessment. Crit Care Med. 1997;25:1095-100.

5. Rothwell PM, Udwadia ZF, Lawler PG. Cortisol response to corticotropin and survival in septic shock. Lancet. 1991;337:582-3.

6. Bollaert PE, Charpentier C, Levy B. Reversal of late septic shock with supraphysiologic doses of hydrocortisone. Crit Care Med. 1998;26:645-50. 
7. Briegel J, Forst H, Haller M, Schelling G, Kilger E, Kuprat G, et al. Stress doses of hydrocortisone reverse hyperdynamic septic shock: a prospective, randomized, double-blind, single-center study. Crit Care Med. 1999;27:723-32.

8. Nylen ES, Muller B. Endocrine changes in critical illness. Intensive Care Med. 2004;19:67-82.

9. Dimopoulou I, Stamoulis K, Ilias I, Tzanela M, Lyberopoulos P, Orfanos $S$, et al. A prospective study on adrenal cortex responses and outcome prediction in acute critical illness: results from a large cohort of 203 mixed ICU patients. Intensive Care Med. 2007;33(12):2116-21.

10. Zipser RD, Davenport MW, Martin KL, Tuck ML, Warner NE, Swinney $R R$, et al. Hyperreninemic hypoaldosteronism in the critically ill: a new entity. J Clin Endocrinol Metab. 1981;53:867-73.

11. Sakharova OV, Inzucchi SE. Endocrine assessments during critical illness. Crit Care Clin. 2007;23:467-90.

12. Vogeser M, Zachoval R, FelbingerTW, Jacob K. Increased ratio of serum cortisol to cortisone in acute phase response. Horm Research. 2002;58:172-75.

13. Tappy L, Chioléro R. Substrate utilization in sepsis and multiple organ failure. Crit Care Med. 2007;35[Suppl.]:S531-4.

14. van der Voort PHJ, Gerritsen RT, Bakker AJ, Boerma EC, Kuiper MA, de Heide L. HDL-cholesterol level and cortisol response to synacthen in critically ill patients. Intensive Care Med. 2003;29:2199-203.

15. Venkatesh B, Cohen J, Hickman I, Nisbet J, Thomas P, Ward G, et al. Evidence of altered cortisol metabolism in critically ill patient: a prospective study. Intensive Care Med. 2007;33:1746-53.

16. Zaloga GP, Marik P. Hypothalamic-pituitary-adrenal insufficiency. Crit Care Clin. 2001;17(1):25-41.

17. Annane D, Sébille V, Troché G, Raphaël JC, Gajdos P, Bellissant E. A 3-level prognostic classification in septic shock based on cortisol levels and cortisol response to corticotropin. JAMA. 2000;283(8):1038-45.

18. Annane D, Maxime V, Ibrahim F, Alvarez JC, Abe E, Boudou P. Diagnosis of adrenal insufficiency in severe sepsis and septic shock. Am J Respir Crit Care Med. 2006;174:1319-26.

19. Beishuizen A, Thijs LG, Vermes I. Patterns of corticosteroid-binding globulin and free cortisol index during septic shock and multitrauma. Intensive Care Med. 2001;27:1584-91.

20. Hamrahian AH, OseniTS, Arafah BM. Measurements of serum free cortisol in critically ill patients. N Engl J Med. 2004;350:1629-38.

21. Bendel S, Karlsson S, Pettilä V, Loisa P, Varpula M, Ruokonen E. Free cortisol in sepsis and septic shock. Anesth Analg. 2008;106(6):1813-9.

22. Dickstein G, Saiegh L. Low-dose and high-dose adrenocorticotropin testing: indications and shortcomings. Curr Opin Endocrinol Diabetes Obes. 2008;15(3):244-9.
23. Dickstein G, Arad E, Shechner C. Low-dose ACTH stimulation test. Endocrinologist. 1997;7:285-93.

24. Beishuizen A, Vermes I, Hylkema BS, Haanen C. Relative eosinophilla and functional adrenal insufficiency in critically ill patients. Lancet. 1999;353:1675-6.

25. Siraux V, De Backer D, Yalavatti G, Mélot C, Gervy C, Mockel J, et al. Relative adrenal insufficiency in patients with septic shock: comparison of low-dose and conventional corticotropin tests. Crit Care Med. 2005;33(11):2479-86.

26. Marik PE, Zaloga GP. Adrenal insufficiency during septic shock. CCM. 2003;31;1:141-5.

27. Annane D, Sébille V, Charpentier C, Bollaert BE, François B, Korach $\mathrm{JM}$, et al. Effect of treatment with low doses of hydrocortisone and fludrocortisone on mortality in patients with septic shock. JAMA. 2002;288(7):862-71.

28. Dellinger RP, Levy MM, Carlet JM, Bion J, Parker MM, Jaeschke $\mathrm{R}$, et al. Surviving Sepsis Campaign: international guidelines for management of severe sepsis and septic shock: 2008. Crit Care Med. 2008;36(1):296-327.

29. Arafah BM, Nishiyama FJ, Tlaygeh $H$, Hejal R. Measurement of salivary cortisol concentration in the assessment of adrenal function in critically ill subjects: a surrogate marker of the circulating free cortisol. JCEM. 2007;92(8):2965-71.

30. Marik PE, Pastores SM, Annane D, Meduri GU, Sprung CL, Arlt $\mathrm{W}$, et al. Recommendations for the diagnosis and management of corticosteroid insufficiency in critically ill adult patients: consensus statements from an international task force by the American College of Critical Care Medicine. Crit Care Med. 2008;36: 1937-49.

31. Castro M, Moreira AC. Análise crítica do cortisol salivar na avaliação do eixo hipotálamo-hipófise-adrenal. Arq Bras Endocrinol Metab. 2003;47(4):358-67.

32. Moraes RB, Czepielewski MA, Friedman G. Is the cortrosyn test necessary in high basal corticoid patients with septic shock? Crit Care Med. 2009;37(1):385-6.

33. Marik PE. Critical illness-related corticosteroid insufficiency. CHEST. 2009;135:181-93.

34. Moraes RB, Czepielewski MA. Corticosteroid therapy for severe sepsis and septic shock. JAMA. 2009;302(15):1643-44.

35. Máxime V, Lesur O, Annane D. Adrenal insufficiency in septic shock. Clin Chest Med. 2009;30:17-27.

36. Annane D, Bellissant E, Bollaert PE, Briegel J, Confalonieri M, De Gaudio $\mathrm{R}$, et al. Corticosteroids in the treatment of severe sepsis and septic shock in adults: a systematic review. JAMA. 2009;301(22):2362-75.

37. Marik PE. Critical illness-related corticosteroid insufficiency. CHEST. 2009;135:181-93. 